\title{
A EDUCAÇÃO INFANTIL COMO CAMPO DE CONHECIMENTO E SUAS POSSÍVEIS INTERFACES COM A EDUCAÇÃOO FÍSICA
}

\author{
Edilayne Fernandes da Silva * \\ Maria do Carmo Morales Pinheiro **
}

\begin{abstract}
RESUMO
Este texto discute a participação da Educação Física na construção da educação infantil como campo de produção de conhecimentos. Assim, são levantados os contextos de produção da educação infantil e Educação Física para compreender em que momento desse trajeto tais áreas se cruzam elaborando um saber comum. Destacamos a pós-graduação em Educação Física no Brasil como elemento determinante desse processo.
\end{abstract}

PALAVRAS-CHAVE: Educação infantil - Educação Física - Campo de conhecimento.

\section{INTRODUÇÃO}

reflexão apresentada aborda a prática pedagógica

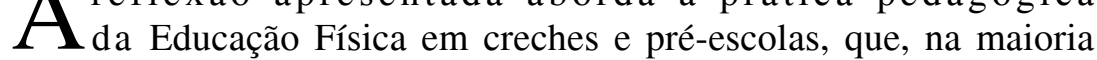
dos casos, ocorre sem a devida fundamentação teórica. Tal panorama aponta para algumas dificuldades no processo da formação profissional, o que nos encaminhou para investigar a formação inicial na Educação Física direcionada às especificidades da educação infantil. Porém, no percurso dos estudos, notamos que havia questões anteriores às de uma formação profissional que abarcasse a especificidade do trabalho em creches e pré-escolas. Uma dessas questões é a necessidade de uma produção teórica voltada a essa

* Professora especialista em Educação Física escolar pela FEF/UFG e efetiva da rede municipal de Aparecida de Goiânia.

** Professora assistente I do curso de Educação Física da UFG/Campus Catalão e orientadora da monografia que deu origem a este texto, intitulada $O$ conhecimento produzido pela Educação Física na educação infantil: um estudo introdutório e defendida em julho de 2001. 
demanda, pois, sem um conhecimento que trate das relações entre a Educação Física e a educação infantil, torna-se difícil requerer dos cursos de formação profissional o atendimento dessa exigência.

Considerando tais aspectos, passamos a questionar o conhecimento produzido pela Educação Física na educação infantil, tendo como fonte de dados os resumos das dissertações e teses da Educação Física catalogados por Silva (1996; 1998). Da monografia citada recortamos justamente a temática ora discutida, ou seja, as possíveis interfaces entre a Educação Física e a educação infantil na construção de um saber comum.

Desse modo objetivamos compreender como a Educação Física, na condição de área de produção de saber, intervém na educação infantil. Ressaltamos as contribuições da pós-graduação tomando por base algumas incursões pelas histórias dessas duas áreas e os resultados da pesquisa mencionada.

\section{A CONSTITUIÇÃO DA EDUCAÇÃO INFANTIL COMO CAMPO DE CONHECIMENTO}

Pressupomos que o acúmulo de pesquisas e reflexões acerca de um dado objeto já constitui per si um certo saber (Demo, 1987; Triviños, 1987), independente de ser ele considerado científico ou não, até porque a ciência não é o único tipo de conhecimento existente, apesar de seu status na modernidade. Além disso, conforme salienta Rocha (1999, p. 57), "todo conhecimento científico é de fato um conhecimento em constante movimento, independente do grau de acabamento de cada campo científico ou de cada ciência". Ou seja, para o autor, o conhecimento é sempre processo, estando em perpétua construção e elaboração através de "processos de definição/redefinição e estruturação/reestruturação de suas bases teóricas que apontam para a descoberta de novos fenômenos" (p. 57). Considerando tais aspectos, pensamos que a educação produz um conhecimento específico que trata das necessidades colocadas por uma prática social, a prática educativa, e das experiências daí decorrentes. Um ponto muito relevante nessa discussão é que 
algumas disciplinas, ou áreas, estão legitimadas no âmbito acadêmico (são reconhecidas, no duplo sentido), em função de seu papel especificamente acadêmico-científico, como fornecedoras, em princípio, de um saber básico que, através de várias mediações, pode alavancar o desenvolvimento tecnológico: é o caso da física, da biologia, da química, da sociologia, da matemática, e suas mais variadas especialidades ou ramificações. Outras foram legitimadas em função da importância de sua intervenção social imediata, como a Medicina e suas correlatas, a Pedagogia/Educação, e outras. Estas últimas estão ligadas, pelas suas características, mais às profissões (para alguns, estas fariam ciências aplicadas, enquanto as primeiras fariam ciências básicas). O reconhecimento destas últimas está, portanto, muito mais vinculado à relevância/legitimidade social de uma prática de intervenção social (para a qual a prática científica deve e pode contribuir), do que a uma possível contribuição acadêmica, que posteriormente seria utilizada nos diferentes campos aplicativos. (Bracht, 2000, p. 58)

Nesse ponto de vista, a configuração das diversas áreas do conhecimento tem raízes no próprio papel social que elas construíram historicamente. Além disso, elas se constituem como campos disciplinares do saber, com finalidades teóricas e práticas, debate este interno às ciências. Conseqüentemente, a legitimidade de cada campo do saber está ligada a sua importância e visibilidade na sociedade.

No caso da educação infantil, é a partir da própria história da assistência à infância que podemos compreender a gênese da produção de um conhecimento que tem como objeto a criança pequena. Segundo Rocha (1999, p. 45), o mesmo movimento que origina uma pedagogia assentada num pacto de controle social

evidencia uma preocupação com a criança e com uma delimitação etária que decorrerá no desenvolvimento de novos campos científicos tais como a Biologia e a Psicologia Infantil, que vão ocupar-se basicamente de uma caracterização das etapas do desenvolvimento infantil. Mais tarde, as Pedagogias, que vinham se desenvolvendo desde o fim do século (entre outros autores: Froebel, Montessori, Decroly e Pestalozzi) ganharão com a Psicologia novos elementos para a invenção de atividades educativas para as crianças dos 'jardins-de-infância', e que se destacaram por diferenciá-las das atividades típicas da escola tradi- 
cional. Esses métodos trarão a base para o desenvolvimento do campo pedagógico que passa a ter como objeto a criança de 0 a 6 anos antes mesmo de se tornar 'aluno' e ingressar na escola convencional.

Mas a emergência da educação infantil como campo de produção de conhecimentos no Brasil pode ser datada da década de 1970, pois até então as intervenções pedagógicas nas creches e préescolas baseiam-se em teorias importadas dos países europeus.

As teorias de Montessori, Froebel, Decroly e Pestalozzi eram as mais veiculadas e consumidas pelas instituições de educação infantil. Até mesmo por conta da dependência cultural do Brasil em relação aos países europeus, considerados mais civilizados, foi cultivada a idéia de que utilizar teorias estrangeiras só poderia trazer o avanço e a modernidade para nosso país. A participação do Brasil nas exposições internacionais, em que eram discutidas e veiculadas tais teorias, comprova essa afirmação (Kuhlmann, 1998).

Segundo Kramer (1987, p. 26),

o conceito de educação compensatória, enfatizado corretamente como um antídoto para a privação cultural, ter-se-ia originado no pensamento de Pestalozzi e Froebel, sendo mais tarde expandido por Montessori e McMillan. Seriam estas suas origens remotas: Froebel iniciando os jardins-de-infância nas favelas alemãs (Berlim), em pleno surgimento da Revolução Industrial; Montessori, ao final do século XIX, e início deste século, desenvolvendo trabalhos de educação pré-escolar voltados para crianças pobres de favelas italianas; McMillan, contemporâneo de Montessori, enfatizando a necessidade de assistência médica e dentária, bem como a estimulação cognitiva, para compensar as deficiências das crianças. A pré-escola era encarada, por esses educadores, como uma forma de superar a miséria, a pobreza, a negligência das famílias.

Ainda as teorias psicanalítica e do desenvolvimento da criança, trazidas ao Brasil após a Segunda Guerra Mundial, nos anos 40, tiveram grande influência no olhar sobre a pré-escola. A atenção voltava-se para as necessidades afetivas da criança, o que resultava em temas como agressão, frustração e ansiedade. Na década de 1950, houve a "redescoberta [...] dos trabalhos teóricos de Montessori, 
Piaget e Vygotsky. A preocupação com os métodos de ensino reaparecia" (Kramer, 1987, p. 28).

Foi justamente nesse período que houve uma maior aproximação do campo educacional com as ciências humanas, principalmente a partir da criação do Centro Brasileiro de Pesquisa Educacional, que teve como objetivo "fundar as bases da reconstrução educacional no Brasil, por uma abordagem multidisciplinar" (Rocha, 1999, p. 70). Porém, no caso da educação infantil, continuou havendo uma grande absorção das teorias estrangeiras em detrimento de um saber produzido por pesquisadores brasileiros. É preciso destacar que não advogamos aqui a produção de um conhecimento que se quer nacionalista, mas salientamos o fato de que há bem pouco tempo as instituições pré-escolares no Brasil eram alimentadas por teorias que não estavam preocupadas com nossa especificidade cultural e social. A constituição de programas e grupos de pesquisa concede certa autonomia à educação infantil no Brasil, que continua dialogando com as teorias geradas em outros países, mas já tem certa independência na elaboração teórica.

Tanto isso é verdade que na década de 1960, mais uma vez, a teoria da privação cultural, reflexo das orientações norte-americanas em educação, se fortalece dando direção às práticas escolares e pré-escolares e sendo criticada apenas nas décadas de 1970 e 1980.

Contudo, essas teorias não se dirigiam especificamente à préescola, mas à escola como um todo, o que demonstra que "o conhecimento científico sobre a pequena infância e sua educação [é] uma elaboração recente que aflora nos últimos trinta anos" (Plaisance e Rayna, apud Rocha, 1999, p. 85). Essa tendência da pesquisa em educação infantil é apontada no mundo inteiro pelos congressos internacionais.

A estruturação de um campo de conhecimentos está intimamente ligada a pesquisas sobre determinados fenômenos atinentes à delimitação de certos objetos de estudo. Tais estudos materializam-se sempre a partir de institutos ou programas de pesquisa, enfim, de instituições responsáveis pela implementação da investigação, sistematização e veiculação dos conhecimentos.

Isso pode ser comprovado pela existência de institutos como o CBPE e o Instituto Nacional de Estudos e Pesquisas Educacionais 
(Inep), que se responsabilizaram, durante um certo período de tempo, pela elaboração e circulação dos conhecimentos relativos à educação. Apesar disso, será apenas nas décadas de 1970 e 1980 que a produção teórica nessa área e, conseqüentemente, na educação infantil tomará um novo e determinante impulso:

a pesquisa educacional ressurgiu no Brasil especialmente com a difusão dos programas de pós-graduação na área da Educação (com significativo crescimento nos anos 80), difusão esta decisiva para o adensamento da produção de pesquisas na área educacional e que tinha como principal objeto a escola e os sistemas de ensino como fenômeno no interior do desenvolvimento do capitalismo. (Rocha, 1999, p. 85)

Percebemos, então, que a produção em educação infantil foi alavancada pela elaboração teórica proveniente dos cursos de pósgraduação em Educação no Brasil. De 1978 a 1981 "o interesse pela pré-escola chegou a $10 \%$ dos trabalhos de pós-graduação em Educação no Brasil" (Gatti, apud Rocha, 1999, p. 84). No período de 1983 a 1996, nota-se um índice de 4,5\% de trabalhos em educação infantil dentre todos os trabalhos de mestrado em Educação. Em nível de doutorado, as teses sobre o assunto atingem o percentual de 3,0\% do total de estudos da área (Rocha, 1999, p. 84).

Também as revistas científicas constituem importante veículo do conhecimento no setor. Já na década de 1970, os Cadernos de Pesquisa, da Fundação Carlos Chagas, foram uma via essencial de sistematização e socialização dos trabalhos sobre educação infantil, materializados sob a forma de artigos. Inclusive, Campos e Haddad (1992), no início dos anos 90, fizeram um mapeamento da publicação destacando a produção que tematizava a educação infantil nos vinte anos de existência da revista.

Um outro dado relevante para compreender a constituição da educação infantil como um campo do saber é a criação da Associação Nacional de Pesquisa em Educação (Anped), em 1978, que, a partir de 1981, garantiu o funcionamento do Grupo Temático sobre Educação Infantil. 
A inclusão da Educação Infantil como um G.T. da ANPED, em 1981, é a expressão do intenso movimento de discussões sobre as políticas sociais e educacionais que marcou aquela década. Inicialmente fundado como G.T. de Educação Pré-escolar e surgindo ao mesmo tempo que outros sete G.Ts com as mesmas características e a mesma sistemática de trabalho, o grupo reuniu pesquisadores e profissionais para constituir um fórum de discussões e debates dos problemas da área. (Rocha, 1999, p. 81)

O próprio contexto de redemocratização da sociedade brasileira na década de 1980 explica o ressurgimento dos movimentos sociais, dos sindicatos e fóruns de discussão, e a criação de associações científicas e demais veículos de debate e produção de conhecimentos. É assim que nasce a Anped, com o intuito de discutir as funções da Educação (acesso, permanência, qualidade etc) em um país capitalista periférico como o Brasil e apontar alternativas de uma educação mais crítica voltada às classes populares. A associação incluía um grupo que discutia o acesso a creches e pré-escolas como um direito e certamente buscou participar dos processos que viabilizaram isso:

O comprometimento com a democratização e a necessidade de um posicionamento frente aos movimentos políticos ligados à definição da nova Constituição Federal em 1988, e mais tarde à Lei de Diretrizes e Bases da Educação Nacional, envolveram intensamente o grupo na busca da formulação de propostas que sustentassem a participação da ANPED neste processo. (Rocha, 1999, p. 82-83)

Certamente o Grupo Temático de Educação de crianças de zero a seis anos da Anped foi determinante no salto qualitativo dado por essa área nos últimos anos no que se refere a sua produção teórica. A intensificação da pesquisa científica sobre a educação infantil nos programas de pós-graduação e a conseqüente expansão das investigações na universidade e nos demais centros de pesquisa, bem como a criação de fóruns de debates e de revistas científicas para sistematizar e veicular o conhecimento gerado, certamente contribuíram na constituição de um campo com corpo próprio de conhecimentos dentro da Educação. Vale lembrar que esta possui 
um objeto de estudo diferenciado da Pedagogia. Segundo Rocha (1999), a educação infantil pode ser considerada como um campo dentro de outro campo de conhecimentos, o que não significa atribuir-lhe nenhum tipo de especialização disciplinar ou mesmo independência em relação à Pedagogia/Educação. Mas apenas reconhecê-la como área que tem por objeto de estudo a criança de zero a seis anos de idade, e não o aluno.

A trajetória das recentes pesquisas em educação infantil aponta para a sua necessária multidisciplinaridade. Em outras palavras, o conhecimento que hoje constitui o campo do saber denominado educação infantil é resultante do entrecruzamento das pesquisas em Educação com aquelas de outras áreas das ciências humanas, quais sejam: Psicologia, Sociologia, Antropologia e outras como Educação Física e Artes. Nesse sentido, a educação infantil pode ser compreendida

como campo de conhecimento que envolve a Infância tomada como objeto por diferentes campos do saber científico nas áreas de saúde, do direito, da sociologia, da história, da antropologia, das ciências humanas e sociais incluindo a demografia, a arquitetura, as artes, as letras, $o$ serviço social, a lingüística, a Educação Física e a Educação, que por sua vez também tem a infância como objeto de estudo e campo de intervenção. (Rocha, 1999, p. 11)

Pois é exatamente nesse ponto que podemos relacionar a educação infantil com a Educação Física, no sentido de esclarecer suas possíveis interfaces na elaboração de um saber que tem como objeto comum (respeitadas as especificidades de cada área) a criança de zero a seis anos, dentro das instituições de educação infantil. Enfim, vislumbramos isso a partir da identificação de

uma acumulação de conhecimentos sobre a Educação Infantil que tem origem em diferentes campos científicos, que além de resultarem em um produto de seu próprio campo, têm resultado em contribuições para a constituição de um campo particular no âmbito da Pedagogia, ao qual venho denominando Pedagogia Infantil e que se inscreve, por sua vez, no âmbito de uma Pedagogia da Infância. (Rocha, 1999, p. 134) 


\section{OS CRUZAMENTOS ENTRE EDUCAÇÃO FÍSICA E EDUCAÇÃO INFANTIL}

A configuração da Educação Física como campo de conhecimentos tem uma história parecida com a da educação infantil, visto que a emergência da pós-graduação em Educação Física e Esportes e a organização de uma entidade científica que congregasse a comunidade acadêmica no Brasil foram fatores decisivos nesse processo.

A década de 1980 é marco de um período em que a Educação Física será repensada como prática social e área de conhecimentos, exatamente no contexto de abertura política do país, no qual foi possível reorganizar e criar entidades representativas da sociedade civil.

Ocorre a fundação do Colégio Brasileiro de Ciências do Esporte $(\mathrm{CBCE})$, entidade científica nacional que objetiva congregar os pesquisadores e demais profissionais da área para debater a Educação Física, principalmente no Congresso Brasileiro de Ciências do Esporte (Conbrace). Além disso, entra em circulação uma revista científica da área no Brasil, a Revista Brasileira de Ciências do Esporte (RBCE), organizada e coordenada pelo CBCE. Isso também é conseqüência de uma política de valorização do fenômeno esportivo no Brasil,

que faz parecer legítimo o investimento em ciência nesse campo, portanto não é gratuita a denominação de Colégio Brasileiro de Ciências do Esporte. É nesse contexto que se afirma a EF nas universidades, possibilitando um discurso científico na área, com reivindicação de cursos de pós-graduação, simpósios científicos, entidades científicas, financiamento de pesquisas científicas [...]. O CBCE é produto e produtor da idéia de cientificização da EF, via as Ciências do Esporte. (Bracht, 1998, p. 15)

Por um lado a maior parte dos trabalhos voltava-se para a fisiologia do exercício, o treinamento desportivo, a biomecânica, o desenvolvimento e a aprendizagem motora, enfim, para o campo 
que daria sustentação ao crescimento do esporte no país. Por outro lado a aproximação com outras ciências humanas foi importante para o delineamento de um novo perfil de Educação Física, que buscou fazer a crítica a essa visão biologicista, privilegiando os debates pedagógicos numa perspectiva progressista.

A partir de referenciais teóricos diversos, procurou-se fazer a crítica à visão biologicista e ao paradigma da aptidão física. Atualmente existe, nesse campo, uma gama de pesquisas que abordam o corpo dos pontos de vista filosófico, antropológico, psicológico, econômico, histórico, sociológico, enfim. Um dos fatores que certamente contribuíram para essa transformação acadêmica é o fato de a comunidade científica da Educação Física ter recorrido aos estudos feitos em outras áreas do conhecimento, enriquecendo sua produção teórica. (Pinheiro, 2000, p. 79)

Também a pós-graduação em Educação Física, fundada em 1977 na USP, em nível de mestrado, teve papel relevante no processo de construção do campo acadêmico da disciplina. A criação desses programas nas universidades no âmbito nacional contou com a defesa da primeira dissertação no ano de 1979. Foram implantados mais adiante outros cursos de mestrado, indicando que "o aumento do número de produções científicas apresenta-se como um ponto extremamente favorável para o desenvolvimento de uma área de conhecimento" (Silva, 1998, p. 19). A produção dos cursos de mestrado e doutorado no Brasil é analisada por Silva (1990, p. 140141), que mapeia as temáticas mais abordadas nas pesquisas:

liderança e esporte; capacidade aeróbica de atletas e escolares, crianças e adolescentes; avaliação antropométrica; aquisição e retenção de habilidade motora; Educação Física no terceiro grau; análise de habilidades motoras em crianças; aptidão física e saúde em escolares; atividades físicas...

É importante ressaltar que, apesar de essas temáticas fazerem parte de uma concepção mais restrita de Educação Física, a ampliação dos debates ocorridos no campo acadêmico - com base em referenciais marxistas que buscavam discutir a transformação social 
- seria fator marcante nos eventos e fóruns que problematizavam essa mesma produção. Afinal, o movimento era de crítica e construção de alternativas para a superação do capitalismo em diversas áreas do conhecimento (por exemplo, a Educação), mesmo que as tendências mostrassem uma Educação Física com caráter biologicista e filiada a uma perspectiva conservadora de sociedade.

No bojo dessas produções encontramos alguns debates acerca dessa disciplina na pré-escola. De maneira ainda tímida, parece que ao colocar a pré-escola e, em alguns casos, a creche, como seu campo de pesquisa, a Educação Física tende a estreitar suas relações com a educação infantil.

Por meio de uma investigação realizada sobre a produção da Educação Física na educação infantil na pós-graduação no período de 1979 a 1997, Silva (2001) detectou que em dezenove anos de elaboração teórica, apenas $3,1 \%$ dos trabalhos ocuparam-se dessa área de pesquisa. Em nível de mestrado, o índice é de 3,2\% do total de dissertações, enquanto em nível de doutorado esse número é de 4,2\%. Apesar desses percentuais, sempre relativos, é importante esclarecer que os programas de doutorado em Educação Física no Brasil são bastante recentes, o que revela estar sob a responsabilidade dos cursos de mestrado a maior produção teórica.

Os números aqui mostrados revelam uma realidade de pesquisa que não privilegia a educação infantil como campo ou objeto de estudo da Educação Física, tornando a produção nessa área incipiente e esparsa. As variadas temáticas mapeadas confirmam esse fato. São elas: ludicidade, Educação Física como componente curricular, psicomotricidade, desenvolvimento motor, aptidão, saúde e nutrição, formação profissional, dança, políticas públicas, expressão corporal e portadores de necessidades especiais. Nota-se que há uma pulverização de interesses de pesquisa, sem apontar para a construção de uma organicidade entre a Educação Física e a educação infantil (Silva, 2001).

Por outro lado, a articulação mais consistente entre a Educação Física e uma certa concepção de educação infantil emerge apenas nas tendências de pesquisa da área, que são três: a psicomotricidade e o desenvolvimento motor (as mais antigas) e a ludicidade, que aparece como tendência dos anos 90. A esse respei- 
to, Sayão (1996) mostra que historicamente as concepções teóricas que influenciaram a Educação Física na pré-escola foram as da recreação, da psicomotricidade e do desenvolvimento motor:

Recreação entendida como compensação de energias gastas pelo massacre da sala de aula ou como desenvolvimento de atividades com fins em si mesmas; Psicomotricidade como instrumental e preparação para as atividades 'futuras' - a alfabetização - ou como metodologia relacional, que se confundiu, pedagogicamente, com a recreação, incentivada por uma certa crença no 'espontaneísmo'; Desenvolvimento Motor que, tendo no esporte de rendimento seu fim último, quando aplicado à Pré-Escola, tenta antecipar o treino de habilidades importantes para a formação de atletas do 'futuro' [grifos da autora]. (Sayão, 1997, p. 265)

Essas tendências trazem implícita uma concepção de educação infantil compensatória, ou seja, um entendimento de que a creche ou a pré-escola são instituições cuja função precípua é compensar as deficiências culturais e do próprio desenvolvimento (físico e intelectual), apresentadas pelas crianças das classes populares, para que as mesmas, mais tarde, não fracassem na escola. Nessa ótica, o movimento ora é tratado como meio de descarga de energias retidas ou frustrações acumuladas, ora como base do desenvolvimento cognitivo, precisando assim ser estimulado, ora como uma forma de apurar as habilidades motoras, que, segundo as teorias da aprendizagem motora, devem ser desenvolvidas desde a mais tenra idade.

Na Educação Física, o desenvolvimento motor e a psicomotricidade representam uma perspectiva de olhar o fenômeno do movimentar-se humano a qual não rompe de modo contundente com o paradigma dominante de pesquisa na área, qual seja, a aptidão física. ${ }^{1}$ Pelo contrário, ambas as teorias estão intimamente relacionadas com o treino das habilidades motoras visando a prática dos esportes. Pressupõe-se que as experiências motoras na infância catalisam uma seqüência normal de desenvolvimento, desencadeando, mais tarde, "o conhecimento cognitivo, pois as primeiras fornecem os meios para que a criança conheça o ambiente e se rela- 
cione com ele" (Sayão, 1996, p. 69). A idéia de movimento como comportamento humano tem seu fundamento nas teorias behavioristas do desenvolvimento humano, que comparam o homem a uma máquina processadora de informações (estímulos), como se fosse possível reduzi-lo aos seus aspectos biológicos e funcionais. Assim, o movimento deve ser instrumentalizado para dar "oportunidade de a criança desenvolver as capacidades motoras básicas e as futuras aprendizagens cognitivas" (Sayão, 1996, p. 70).

A psicomotricidade, por sua vez, apesar de tentar romper com a idéia de especialização precoce, não avança no sentido das teorias do desenvolvimento e da aprendizagem que a sustentam, pois mantém a idéia espontaneísta do desenvolvimento humano como algo que ocorre 'naturalmente'. Para Sayão (1996, p. 66), a psicomotricidade instrumental

esteve, certamente, a serviço de uma concepção preparatória de préescola. Havia a crença de que as crianças que desenvolvessem um bom conhecimento do esquema corporal, p. ex., teriam a probabilidade 'natural' de se alfabetizarem com mais facilidade e sucesso. Pode-se aferir que o principal papel atribuído à Psicomotricidade Instrumental foi de tentar evitar o fracasso na primeira série.

Percebe-se, então, que a intenção de instrumentalização do movimento humano persiste, o que mantém um entendimento reducionista dos processos de aprendizagem e desenvolvimento humano. Ademais, essa instrumentalização não faz frente às abordagens funcionalistas de corpo, homem, educação e sociedade, visto que não problematiza as questões pertinentes à inserção cultural das crianças.

A realidade é que a expansão da pós-graduação em Educação Física no Brasil sempre esteve ligada ao desenvolvimento do paradigma da aptidão física, donde a maior parte das linhas de pesquisa dos próprios programas privilegiava estudos dessa natureza (Silva, 1997). Nesse contexto, é até normal que o olhar sobre a Educação Física na pré-escola carregue as marcas de uma visão de corpo biologizado e fragmentado da sociedade e que haja uma despreocupação quanto à perspectiva educativa das instituições de educa- 
ção infantil. Afinal, percebemos que ao mesmo tempo em que a comunidade científica da educação infantil já elabora uma crítica à visão de educação compensatória, e isso ocorre ainda na década de 1980, a maioria dos trabalhos produzidos nos programas de pósgraduação em Educação Física no Brasil - centrados na relação entre esses dois campos e realizados nesse mesmo período - reforça aquela concepção. Nota-se uma disparidade na produção dessas duas áreas, apesar de estarem, cada uma a seu modo, elaborando um saber comum. Nesse sentido, Sayão (1996, p. 14) afirma que

a produção teórica destes dois campos, quando analisados imbricadamente, mostra que não existe uma educação física infantil voltada para as características de aprendizagem e desenvolvimento desta faixa etária, apropriando-se da discussão acumulada pela educação da criança de 0 a 6 anos [e] problematizando as interfaces em torno do conhecimento da criança, das pedagogias e das políticas que aproximam ou distanciam estes campos do saber.

O contraponto a essa realidade é o crescimento do número de dissertações e teses que abordam questões pertinentes à educação infantil de maneira mais articulada a ela, o que ocorre a partir do ano de 1996. Enfim, é justamente nesse momento que as temáticas de pesquisa são ampliadas para o campo do desenvolvimento infantil com perspectivas mais críticas, como a sócio-histórica e ecológica do desenvolvimento humano.

Nota-se, inclusive, que, ao mesmo tempo em que emergem preocupações de estudos voltados aos portadores de necessidades especiais, ao brincar e às perspectivas da Educação Física como componente curricular da pré-escola e/ou creche - o que denota uma ampliação do olhar sobre esse campo de investigação -, o interesse pela psicomotricidade e pelo desenvolvimento motor é visivelmente menor (Silva, 2001).

A própria tendência da ludicidade, vislumbrada a partir dos anos 90, indica uma certa mudança de percepção sobre a Educação Física na educação infantil, já que o brincar e o brinquedo tornamse temas de pesquisa da área. Contudo, é preciso destacar que isso por si só ainda não garante que essas investigações apresentem um 
entendimento mais crítico e articulado com as discussões da educação infantil. Afinal, existem diferentes modos de ver e construir os objetos de estudo, no caso aqui tratado, o brinquedo.

De qualquer modo, o reconhecimento de alguns pesquisadores da área em relação ao papel do brinquedo no desenvolvimento e na aprendizagem da criança, assim como a responsabilidade que o professor de Educação Física pode exercer nesses processos, representa um avanço na direção da possibilidade de construirmos uma relação mais orgânica com a educação infantil. Coerentemente com esse cenário, os estudos feitos por Garanhani (2000, p. 37) sobre a motricidade voltada para a educação infantil demonstram que essa produção

se manteve estável no período de 1983 a 1995, havendo um crescimento, a partir de 1996, devido ao número de dissertações defendidas com temáticas em torno da Educação Física na Educação Infantil. Isto revela um crescimento da inserção dos profissionais da área da Educação Física nos programas de pós-graduação em educação no Brasil.

Percebemos que também o ingresso de alguns pesquisadores da Educação Física na pós-graduação em Educação no Brasil contribuiu para ampliar a visão de corpo, movimento, homem e mundo dos trabalhos elaborados, bem como os estudos centrados nessa disciplina e na educação infantil. Principalmente em um momento em que esta vem recebendo mais atenção e incentivos, até mesmo por parte do MEC - responsável pela elaboração do Referencial curricular nacional para a educação infantil, que tem como um de seus eixos o movimento corporal da criança pequena -, é extremamente importante que nos debrucemos com mais afinco sobre esse tema de pesquisa. Até porque,

apesar de as orientações curriculares para a Educação Infantil no Brasil apresentarem uma preocupação em torno da organização de um ambiente educativo que contemple as diversas áreas do desenvolvimento infantil, bem como as diferentes linguagens da pequena infância, observa-se [...] uma baixa produção teórica em torno da motricidade infantil na área da educação brasileira. Este cenário sugere que os movimentos do corpo infantil não são priorizados no trato pedagógico da criança de 
0 a 6 anos e nem pelos pesquisadores da área da educação, como temática de investigação. (Garanhani, 2000, p. 38-39)

Convém ressaltar, portanto, a urgência de propostas metodológicas coerentes com uma perspectiva de educação crítica e da oposição aos modismos tão freqüentes e oportunistas que, vez por outra, assaltam a formação de nossas crianças.

Nesse sentido, é importante enfatizar o papel fundamental que a pós-graduação em Educação Física e a inserção de pesquisadores desta área na pós-graduação em Educação tiveram no delineamento de uma trajetória que contribuiu para a constituição da própria educação infantil. E que, apesar dos distanciamentos, construíramse pontos de intersecção bastante interessantes.

\section{CONSIDERAÇÕES FINAIS}

Quando o campo de intervenção da Educação Física é a creche ou a pré-escola, seu objeto de estudo passa a ser o movimento ou o corpo da criança pequena, esta última, objeto da educação infantil. Se considerarmos que a problemática da Educação Física pode ser o "o movimentar-se humano e suas objetivações culturais na perspectiva de sua participação/contribuição para a educação do homem" (Bracht, 2000, p. 61), parecer-nos-á mais do que justificável que essa área pode e deve contribuir para o repensar do corpo, do movimento e da cultura corporal da criança pequena na creche e na pré-escola. Seria essa contribuição uma forma de contrariar os índices que apontam para a parca reflexão acerca dessa temática na educação infantil e na própria Educação Física.

Pensamos ser possível vislumbrar a participação crítica dessa disciplina na constituição de uma pedagogia da educação infantil (Rocha, 1999), o que ajudaria a refletir as demandas dessa área e construir propostas de intervenção que não esqueçam o cuidar e o educar como princípios. Até porque, mesmo que se pense em outra divisão disciplinar dentro da Educação Física, que resultaria numa espécie de Educação Física Infantil, tal área deverá estar disposta a colaborar para a consolidação da educação infantil como um cam- 
po de conhecimentos que, para existir, necessariamente se cruza com outros campos do saber.

Infant Education as a Field of Knowledge and Its Possible Interfaces with Physical Education

\begin{abstract}
This text discusses the participation of Physical Education in the construction of Infant Education as a field for the production of knowledge. We investigate the contexts of production for Infant Education and Physical Education in order to understand at what point theses two areas cross one another and build knowledge on common grounds. We highlight post-graduation courses of Physical Education in Brazil as a key element in this process.
\end{abstract}

KEY WORDS: Infant education - Physical Education - Field of knowledge.

\title{
NOTA
}

1. Segundo Silva (1997), epistemologicamente esse paradigma se apóia no método positivista e é representado pelas pesquisas empírico-analíticas, que, em termos filosóficos, apresentam uma visão estática e fragmentada dos fenômenos sociais.

\section{REFERÊNCIAS}

BRACHT, V. Um pouco de história para fazer história: 20 anos de CBCE. Revista Brasileira de Ciências do Esporte, n. especial, p. 12-18, set. 1998.

Educação Física \& Ciência: cenas de um casamento (in)feliz. Revista Brasileira de Ciências do Esporte, v. 22, n. 1, p. 53-64, set. 2000.

CAMPOS, M. M.; HADDAD, L. Educação Infantil: crescendo e aparecendo. Cadernos de Pesquisa, São Paulo, n. 80, p. 11-12, fev. 1992.

DEMO, P. Introdução à metodologia da ciência. 2. ed. São Paulo: Atlas, 1987. 
GARANHANI, M. C. A motricidade nos estudos da Educação Infantil no Brasil: uma análise da produção teórica na área da Educação (1983-1998). Revista de Educação da UFPR, Curitiba, v. 1, n. 2, p. 31-39, nov. 2000.

KRAMER, S. A política do pré-escolar no Brasil. 3. ed. Rio de Janeiro: Dois Pontos, 1987.

KUHLMANN JÚNIOR, M. Infância e Educação Infantil. Porto Alegre: Mediação, 1998.

PINHEIRO, M. do C. M. 'Quietinho, sentado obedecendo a professora': a representação do corpo da criança na pré-escola. 2000. 243 f. Dissertação (Mestrado) - Fauldade de Educação, Universidade Federal de Goiás, Goiânia.

SAYÃO, D. T. Educação Física na pré-escola. 1996. 143 f. Dissertação (Mestrado) - Faculdade de Educação, Universidade Federal de Santa Catarina, Florianópolis.

. A hora de... Educação Física na pré-escola. Anais do X Conbrace, Goiânia, v. 1, p. 261-268, out. 1997.

SILVA, E. F. O conhecimento produzido pela Educação Física na Educação Infantil: um estudo introdutório. 2001. 74 f. Monografia (Especialização) - Faculdade de Educação Física, Universidade Federal de Goiás, Goiânia.

SILVA, R. de S. Mestrados em Educação Física no Brasil: pesquisando suas pesquisas. 1990. $236 \mathrm{f}$. Dissertação (Mestrado) Universidade Federal de Santa Maria, Santa Maria.

Pesquisa em Educação Física: determinações históricas e implicações epistemológicas. 1997. 278 f. Tese (Doutoramento) - Universidade de Campinas, Campinas.

ROCHA, E. C. A pesquisa em Educação Infantil no Brasil: trajetória recente e perspectiva de consolidação de uma Pedagogia da Educação Infantil. Florianópolis: Ed. UFSC, 1999.

TRIVIÑOS, A. N. S. Introdução à pesquisa em ciências sociais. São Paulo: Atlas, 1987. 
Recebido: Setembro de 2002 Aprovado: Novembro de 2002

Endereço para correspondência Edilayne Fernandes da Silva Rua 236, no 121, S-107 Setor Universitário Goiânia - Goiás CEP 74610-070

Maria do Carmo Morales Pinheiro

Rua 19, no 55 - Ap. 1202

Ed. Dom Abel - Centro

Goiânia - Goiás

CEP 74030-090 